Manuscript for J. Matter. Chem. C., Garrett, et al.

\title{
Synthesis and Thermoelectric Properties of 2- and 2,8-Substituted Tetrathiotetracenes ${ }^{\dagger}$
}

Mary Robert Garrett, ${ }^{a}$ María Jesús Durán-Peña, ${ }^{a}$ William Lewis, ${ }^{b}$ Kaspars Pudzs, ${ }^{c}$ Janis Uzulis, ${ }^{c}$ Igors Mihailovs, ${ }^{c}$ Björk Tyril, ${ }^{a}$ Jonathan Shine, ${ }^{a}$ Emily F. Smith, ${ }^{d}$ Martins Rutkis, ${ }^{* c}$ and Simon Woodward*a

a GSK Carbon Neutral Laboratories for Sustainable Chemistry, Jubilee Campus, University of Nottingham, Nottingham NG7 2TU, United Kingdom.

b School of Chemistry, University Park Campus, University of Nottingham, Nottingham NG7 2RD, United Kingdom.

c Institute for Solid State Physics, University of Latvia, 8 Kengaraga Street, LV-1063 Riga, Latvia.

d Nanoscale and Microscale Research Centre (nmRC), School of Chemistry, University Park Campus, University of Nottingham, Nottingham NG7 2RD, United Kingdom.

\begin{abstract}
Reaction of elemental sulfur with $2-R^{1}$ and $2,8-R^{1}, R^{2}$-substituted tetracenes (2) in refluxing DMF affords 5,6,11,12 tetrathiotetracenes (1) in good yields (74-99\%) for a range of substituents where $\mathrm{R}^{1}, \mathrm{R}^{2}$ are: $\mathrm{H}, \mathrm{H}(\mathbf{a}) ; \mathrm{Me}, \mathrm{H}(\mathbf{b}) ; \mathrm{MeO}, \mathrm{H}(\mathbf{c}) ; \mathrm{Ph}, \mathrm{H}(\mathbf{d}) ; \mathrm{Me}, \mathrm{Me}(\mathbf{e}), i \mathrm{Pr}, \mathrm{Me}(\mathbf{f}, i \mathrm{Pr}$ = iso-propyl, $\left.\mathrm{CHMe}_{2}\right), \mathrm{Me}, \mathrm{MeO}(\mathbf{g}) ; \mathrm{MeO}, \mathrm{MeO}(\mathbf{h})$. The reaction rate is limited only by the solubility of the tetracene $(\mathbf{2}) ; \mathbf{2} \mathbf{g}-\mathbf{h}$ being both the least soluble and slowest reacting. At partial conversion recovered single crystalline $\mathbf{2 g}$ led to its X-ray structure determination. Vacuum deposited (substrate deposition temperature $300 \mathrm{~K}$, pressure $7 \times 10^{-6} \mathrm{mbar}$, source temperature $500 \mathrm{~K}$ ) thin films from 1 (of initial $88-99 \%$ purity) show final electrical conductivities, $\sigma_{\text {(in plane) }}$ from $1.40 \times 10^{-5} \mathrm{~S} \mathrm{~cm}^{-1}(\mathbf{1 g})$ to $3.74 \times 10^{-4} \mathrm{~S} \mathrm{~cm}^{-1}(\mathbf{1 b})$ for the resultant near pristine films; while 1d proved too involatile to be effectively sublimed under these conditions. In comparison, initially $95 \%$ pure $\Pi T$ (1a) based films show $\sigma_{\text {(in plane) }}=4.33 \times 10^{-5} \mathrm{~S} \mathrm{~cm}^{-1}$. The purities of 1a$\mathbf{h}$ are highly upgraded during sublimation. Well defined micro-crystallites showing blade, needle or mossy like habits are observed in the films. The Seebeck coefficients $\left(S_{b}\right)$ of the prepared $\mathbf{1}$ range from 374 (1c) to 900 (1f) $\mu \mathrm{V} \mathrm{K}^{-1}$ (vs. $855 \mu \mathrm{V} \mathrm{K}^{-1}$ for identically prepared $95 \%$ pure TT, 1a). Doping of films of $\mathbf{1 f}\left(\mathrm{R}^{1}=i \mathrm{Pr}, \mathrm{R}^{2}=\mathrm{Me}\right)$ with iodine produces optimal $\mathrm{p}$-type behaviour: $\sigma_{\text {(in-plane) }}=7.00 \times 10^{-2} \mathrm{~S} \mathrm{~cm}^{-1}, S_{b}=175 \mu \mathrm{V} \mathrm{K}^{-1}$. The latter's Power Factor $(P F)$ at $0.33 \mu \mathrm{W} \mathrm{m} \mathrm{K}^{-1} \mathrm{~K}^{-2}$ is more than 500-times that of the equivalent $I_{2}$-doped $\Pi T$ films $\left(\mathbf{1} \mathbf{a}, R^{1}=R^{2}=H\right)$, previously regarded as the optimal material for thin film thermoelectric devices using acene radical cation motifs.
\end{abstract}

\section{Introduction}

Organic thermoelectric (OTE) materials offer new opportunities for sustainable waste heat recovery, personalised power (via body heat use) and microcooling (via the Peltier effect). ${ }^{1}$ Present OTE development is dominated by the use of polymeric thiophenes, primarily PEDOT [poly(3,4-ethylenedioxythiophene)] based materials. For such polymers only formulation approaches are appropriate for optimising TE performance as opportunities for structural modification of the PEDOT itself are highly limited.

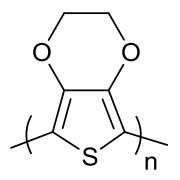

PEDOT

${ }^{+}$Electronic supplementary information (ESI) available. 
Manuscript for J. Matter. Chem. C., Garrett, et al.

Recently, radical cation salts of electron-rich acene tetrathiotetracenes (TTTs) (Scheme 1) emerged as a new class of materials for OTE device preparation. ${ }^{2}$ Such TTT cores are highly suited to derivatisation (via position 1-4 or 7-10 functionalisation). Such derivitisation is expected to strongly affect the thermoelectric properties of the conducting states formed upon oxidation of the TTT core potentially leading to improved or tunable OTE performance. However, derivatives of the parent $\Pi \pi$ molecule $\mathbf{1 a}$ are rare and their thermoelectric performance [especially Seebeck coefficients $\left(S_{b}\right)$ ] remain essentially unknown. ${ }^{3}$ We aim to synthesise new tetrathiotetracene derivatives $\mathbf{1}$ by convenient, easily implemented, scalable, reproducible procedures. While the unsubstituted $\Pi T\left(\mathbf{1} \mathbf{a}, \mathrm{R}^{1}=\mathrm{R}^{2}=\mathrm{H}\right)$ has been known for over 70 years and has attracted widespread use in organic electronics, ${ }^{4}$ extensive investigations of even its simplest derivatives are scant (being limited to early Soviet literature or partial claims in industrial patents). ${ }^{5}$ Only a handful of 2-, 2,3- and 2,3,8,9-derivatives (often with limited or no data supporting the structures) are available (due to difficulties in their preparation and purification) and none has had its thermoelectric behaviour described. ${ }^{3,5}$ We proposed to prepare both known and unknown 2 and 2,8-substituted tetrathiotetracenes (1)-g) and to establish a high-throughput screening protocol for comparison of the thermoelectric properties of new derivatives to the parent TTT 1a. Our aim was to identify new optimal TTT derivative cores with high $S_{b}$ values for future use in energy recovery devices operating at lower temperatures (ca. $150{ }^{\circ} \mathrm{C}$ and below). ${ }^{2}$ There is a clear reason to target such materials: the power output of a OTE device is directly proportional to $\left(S_{b}\right)^{2}$. However, most present materials, when doped for optimal OTE behaviour, show relatively low $S_{b}$ values (e.g. $10-50 \mu \mathrm{V} \mathrm{K}^{-1}$ ). ${ }^{1 a}$

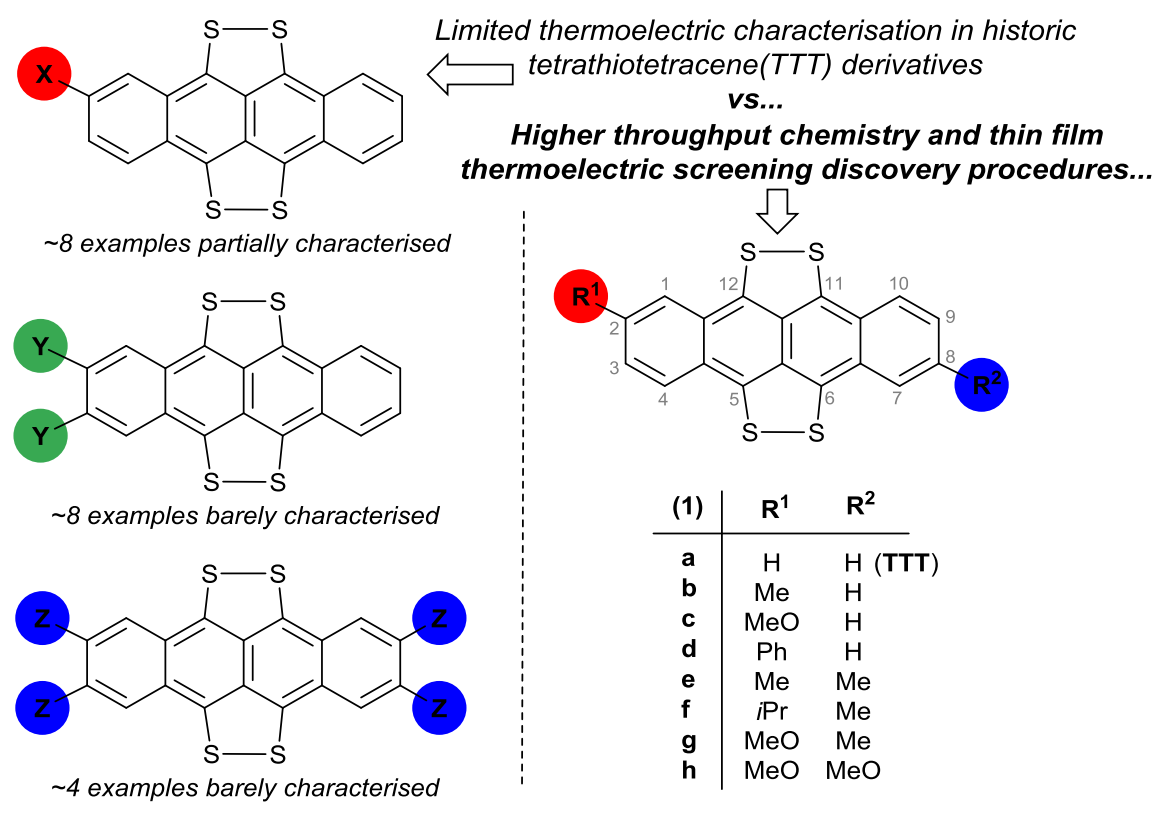

Scheme 1. Known and new substituted tetrathiotetracenes (TTT is reserved for the parent 1a; most known derivatives are from the patent literature of 1985-2000; X-Z = alkyl derivatives, ether or amine derivatives, carbonyl derivatives, halide, $\mathrm{CF}_{3}$, thiopyridyl). ${ }^{5}$ Many are only patent claimed structures and are at best partially characterised species. The small grey numbers show the approved IUPAC numbering for substituted tetracenes.

\section{Results and Discussion}

Tetrathiotetracene synthesis. Direct reaction of readily available tetracenes $(\mathbf{2} \mathbf{a}-\mathbf{h})^{6}$ with elemental sulfur in DMF at reflux, in the manner of Perez-Alberne, ${ }^{7}$ afforded the 
Manuscript for J. Matter. Chem. C., Garrett, et al.

tetrathiotetracenes (1a-h) (Table 1 ). All are readily isolated in good yields (74-99\%) as very dark green powders by simple filtration of the hot reaction mixtures giving products with purities of ca. $90 \%$. While many tetrathiotetracenes 1 can be sublimed under very high vacuums $\left(<10^{-6}\right.$ mbar), at the more modest pressures attainable in most synthetic laboratories (ca. $0.1 \mathrm{mbar}$ ) significant decomposition results at the higher temperatures ( $>270{ }^{\circ} \mathrm{C}$ ) needed to engender significant volatility. However, simple removal of residual solvents and $\mathrm{S}_{8}$ at $140{ }^{\circ} \mathrm{C} / 0.1 \mathrm{mbar}$ is easily achieved for directly precipitated samples of $\mathbf{1 a - h}$, whose spectroscopic properties are entirely consistent with the proposed structures. Only traces of non-volatile inorganic byproducts remain for such 'precipitated' samples of $\mathbf{1}$, which typically assay as $88-99 \%$ pure by CHN analytical techniques. Such easily prepared samples are ideal for initial thin film thermoelectric property screening as only $\mathbf{1}$ sublimes during film deposition leading to enrichment to near pristine $(>99 \%)$ material upon sublimation (see later). A significant advantage of this 'direct precipitation'/S8 removal/sublimation approach is that many more TTT derivatives can be prepared and screened per unit time compared the traditional approaches (where multiple purifications by either recrystallisation or sublimation are normally required) prior to measurement of the $\Pi \pi$ thermoelectric properties. ${ }^{3}$ The lowest purity $\Pi \pi$ derivatives (1) we attained were consistently associated with structures $\mathbf{1 c}\left(R^{1}=\mathrm{MeO}, \mathrm{R}^{2}=H\right)$ and $\mathbf{1 h}\left(R^{1}\right.$ $\left.=\mathrm{R}^{2}=\mathrm{MeO}\right)$. Tetrathiotetracenes containing methoxy functions are somewhat more air sensitive than other derivatives (bulk samples of $\mathbf{1 h}$ were fully degraded within three months under ambient conditions in the solid state). However, all our $\Pi \pi$ derivatives 1a-h slowly (over $>10$ days) underwent partial aerial degradation when bulk samples were stored at ambient temperature in the dark in air. Because of this it is recommended that all of the substituted tetrathiotetracenes $\mathbf{1 b}-\mathbf{h}$ are kept under an inert atmosphere at $-20{ }^{\circ} \mathrm{C}$, although they may all be handled in air over a few hours without ill effect. We had previously seen that thin films of $\Pi T\left(\mathbf{1} \mathbf{a}, \mathrm{R}^{1}=\mathrm{R}^{2}=\mathrm{H}\right)$ showed related aerial oxidative modification on extended exposure to air. $^{2 c}$

Preparative details and solution electro-optic properties of the tetrathiotetracenes (1) are given in Table 1. Typically the reactions were conducted at 0.2 to $1 \mathrm{mmol}$ scales (ca. $50-200 \mathrm{mg}$ ) but these could be scaled up to gram amounts without deleterious effects.

Table 1. Synthesis of tetrathiotetracenes (1) and their optical properties. ${ }^{a}$

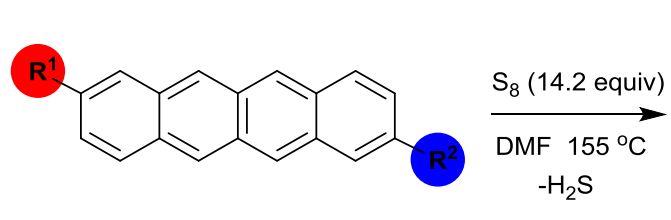

(2)

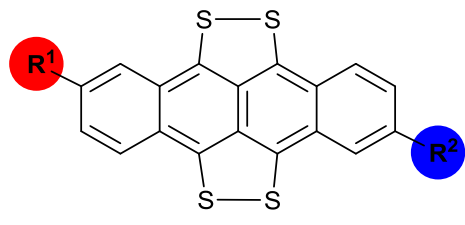

(1)

\begin{tabular}{cccccccc}
\hline No. & {$[\mathbf{2}](\mathrm{M})$} & $\mathrm{R}^{1}$ & $\mathrm{R}^{2}$ & Time $(\mathrm{h})$ & Yield 1 $(\%)$ & $\lambda \max (\mathrm{nm})$ & $\mathrm{E}_{\mathrm{g}}(\mathrm{opt})(\mathrm{eV})$ \\
\hline $\mathbf{1 a}$ & 0.15 & $\mathrm{H}$ & $\mathrm{H}$ & 5 & 86 & 695 & 1.53 \\
$\mathbf{1 b}$ & 0.15 & $\mathrm{Me}$ & $\mathrm{H}$ & 5.5 & 86 & 691 & 1.61 \\
$\mathbf{1 c}$ & 0.15 & $\mathrm{MeO}$ & $\mathrm{H}$ & 5 & 80 & 687 & 1.59 \\
$\mathbf{1 d}$ & 0.15 & $\mathrm{Ph}$ & $\mathrm{H}$ & 5 & $>99$ & 707 & 1.59 \\
$\mathbf{1 e}$ & 0.15 & $\mathrm{Me}$ & $\mathrm{Me}$ & 18 & 89 & 686 & 1.51 \\
$\mathbf{1 f}$ & 0.15 & $i \mathrm{Pr}$ & $\mathrm{Me}$ & 18 & 74 & 684 & 1.59 \\
$\mathbf{1 g}$ & 0.07 & $\mathrm{Me}$ & $\mathrm{MeO}$ & 18 & 88 & 682 & 1.54 \\
$\mathbf{1 h}$ & 0.045 & $\mathrm{MeO}$ & $\mathrm{MeO}$ & 168 & 75 & 671 & 1.62 \\
\hline
\end{tabular}


a Typically reactions were carried out on ca. $0.2-1 \mathrm{mmol}$ scales in DMF at the nominal concentrations given (initially $\mathbf{2}$ is insoluble in DMF) under inert atmospheres.

Interestingly, the rate of formation of $\mathbf{1}$ from $\mathbf{2}$ is essentially independent of the electronic donor/acceptor properties of the substituents within $\mathbf{1}$ in the eight cases tried. The solubility of $\mathbf{2}$ in refluxing DMF appears to be the more important factor. For the least soluble tetracenes ( $\mathbf{2 g}-\mathbf{h})$ the reactions were sluggish and needed an extended heating period and sometimes the use of more dilute solutions. It was found that at partial conversion ( $5 \mathrm{~h}$ ) X-ray quality crystals of $\mathbf{2 g}$ could be recovered from experiments aimed at providing the $\Pi \pi$ derivative $\mathbf{1 g}$. The structure of $\mathbf{2 g}$ (Figure $1 \mathrm{~A}$ ) shows packing motif features that are classical herringbone-type interactions. In particular, the closest intermolecular distances are $\mathrm{C}-\mathrm{H}$.... $\mathrm{C}_{\text {ipso }}$ contacts that range 2.94-2.95 $\AA$ In comparison, $\mathrm{C}-\mathrm{H}$.... Cipso contacts are absent in a representative literature TTT (1a) X-ray crystal structure (CCDC code: NPDTOL). ${ }^{8}$ The closest intermolecular interactions in this structure are between the S-S units and the phenylene units (S...C-H 3.45-3.68 $\AA$ ) and between the disulfide units themselves (S-S...S-S 3.75-5.11 $\AA$ ); leading to a greater tendency for face-face interaction (Figure 1B). Attempts to attain single crystals of any of the TTT derivatives $\mathbf{1 b}$-h have, thus far, been unsuccessful. The anomalous slow reactivity of $\mathbf{1 h}$ appears to be due to initial formation of an intermediate $1: 1$ adduct between the parent tetracene and tetrathio-derivative ( $\mathbf{1 h} \cdot \mathbf{2 h}$ ) that has very low solubility in DMF resulting in very slow subsequent formation of $\mathbf{1 h}$. Despite its low solubility, ${ }^{1} \mathrm{H}$ NMR spectra of the adduct (1/h.2h) confirm its $1: 1$ constitution. The chemical shift differences of the signals in the adduct vs. the pure components $\mathbf{1 h}$ and $\mathbf{2 h}$ also supports the formation of a new material. While $\Pi \pi$ (1) $\mathbf{a}$ ) is widely used in organic electronic applications, one limitation is its very low solubility (ca. $0.3 \mathrm{mM}$ in toluene and ca. $3 \mathrm{mM}$ in $\mathrm{CS}_{2}$ ). We hoped that some of the derivatives prepared here would have higher solubility, but in fact only marginal gains were made testifying to the high degree of $\Pi-\pi$ stacking in these systems. Compound $\mathbf{1 f}$ showed the highest solubility about 2-3 times that of TाT (1a) depending on solvent choice, while $\mathbf{1 h}$ showed the lowest (about a quarter of that of TTT, 1a).

Figure 1. Packing diagrams for (A) tetracene $\mathbf{2 g}$ and (B) TTT 1a (structure NPDTOL from the Cambridge Crystallographic Database) $i^{8}$ hydrogen atoms are not shown for clarity.

(A)

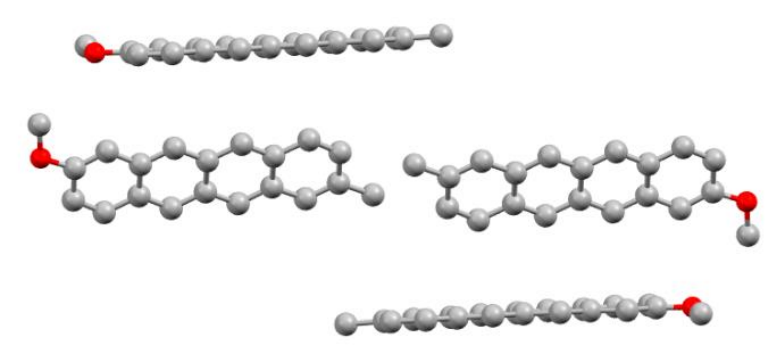

(B)

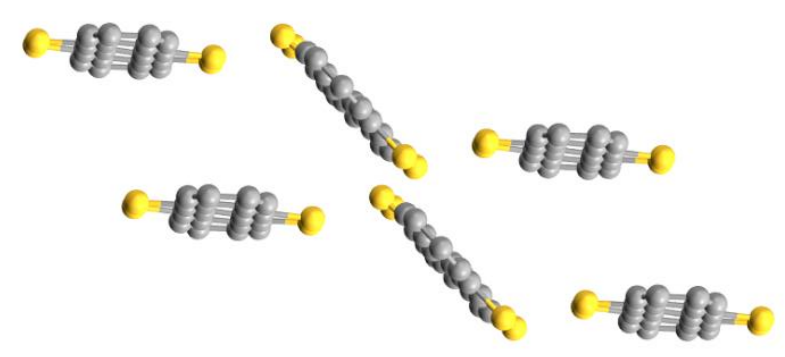

UV-vis spectra of forest green $\mathrm{CH}_{2} \mathrm{Cl}_{2}$ solutions of $\mathbf{1}$ reveal the presence of 4-5 bands; the intensity of the lowest energy band maximises at $\sim 700 \mathrm{~nm}$. Onset (Tauc) plots of this band indicate optical bandgaps of in the range 1.53-1.62 eV which are only slightly affected by the nature of the substituents within $\mathbf{1}$ (see Table 1 ). The optical band gap in all of the tetrathiotetracenes $\mathbf{1}$ is significantly lower than the $E_{g}$ (opt) in the parent tetracenes $\mathbf{2 a - g}$ which range 2.43-2.54 eV (see ESI). To further confirm that the substituents in our substituted 
Manuscript for J. Matter. Chem. C., Garrett, et al.

tetrathiotetracenes $\mathbf{1 b}$-h do affect the electronic states of compounds, representative examples had their ionisation energies (IEs) ${ }^{9}$ determined by photoemission spectroscopy (on deposited films, see ESI). ${ }^{10}$ Values of $-4.55 \mathrm{eV}\left(T T T, R^{1}=R^{2}=H, 1 \mathbf{a}\right),-4.59 \mathrm{eV}\left(R^{1}=R^{2}=\right.$ Me, 1 e $),-4.52$ $\mathrm{eV}\left(\mathrm{R}^{1}=i \mathrm{Pr}, \mathrm{R}^{2}=\mathrm{Me}, \mathbf{1 f}\right), 4.60 \mathrm{eV}\left(\mathrm{R}^{1}=\mathrm{R}^{2}=\mathrm{OMe}, \mathbf{1 h}\right)$ were determined. Calculated values (by $\triangle \mathrm{SCF}$, medium-polarized; see ESI) of the IEs were within 2-6\% of the experimentally determined values. Additionally, transport band gaps $E_{g}(T)$ were estimated to be 2.32-2.51 eV (see ESI) in these calculations. As is typical, values of $E_{g}(T)$ are greater than $E_{g}(o p t) .{ }^{10}$

Thin film studies. Thin films of $\Pi \Pi \mathrm{T}(\mathbf{1 a})$ and the substituted tetrathiotetracenes $\mathbf{1} \mathbf{b}-\mathbf{h}$ were prepared by thermal evaporation of freshly prepared samples of $\mathbf{1}$ under reduced pressure (see ESI) as described by us previously. ${ }^{2 b}$ This procedure results in a significant upgrade in the purity of the deposited tetrathiotetracenes $\mathbf{1} \mathbf{a}-\mathbf{h}$. In order to confirm the validity of this assumption a number of control experiments (ESI, Section 6) were carried out: (i) The behaviour of already pristine 1a (previously attained by vapour transport crystallisation ${ }^{2 a}$ ) was compared to the $95 \%$ purity 1a prepared here by our high throughput 'direct precipitation' procedure (Table 2 ). The in-plane electrical conductivity (entries 1-2, Table 2) of the pristine and 'direct precipitated' 1a were within a factor of 1.8 of each and within a factor of 1.4 on Seebeck coefficient $\left(S_{b}\right)$. (ii) Initially $88 \%$ pure $\mathbf{1 h}$ (the TT material most sensitive to aerial oxidation and at the lowest purity used herein) was subjected to sublimation under conditions identical to those used to prepare thin films. The post-sublimed dark green micro-crystalline material was confirmed to be $>99 \%$ pure by ${ }^{1} \mathrm{H}$ NMR, IR, MS and elemental analysis. (iii) IR studies on the deposited TTT films are identical to those of the pre-deposited (single organic component by ${ }^{1} \mathrm{H}$ NMR spectroscopy) materials indicating that only the TTT derivatives $\mathbf{1}$ are deposited. (iv) XPS analysis (O $1 \mathrm{~s}$ adsorption) of films of $\mathbf{1 e}$ indicate no evidence of significant aerial oxidation (0.05-0.3 \pm 0.2 atomic \%), even after handling in air for several hours (Figure S7a, ESI). Although the very minor residual impurities in the TT derivatives $\mathbf{1 a - h}$ prepared here do cause some increase in the $\sigma_{\text {(in-plane) }}$ conductivity and degradation in $S_{b}$ performance, this is small compared to the key substituent effects modifying the behaviour of the parent $\Pi T$ to be detected by our screening approach. Identification of improved $\Pi T$ materials is therefore straightforward (e.g. the highlighted $S_{b}$ performance of $\mathbf{1 f}$ ) using films from the 'direct precipitation' samples prepared above. Based on the validations above, the behaviour of $\mathbf{1} \mathbf{b}-\mathbf{h}$ (from samples of $88-98 \%$ purity) was compared to $\Pi T(\mathbf{1 a})$. Three archetypical film morphologies were observed: blade like morphologies (as previously reported for TTT 1a, but also seen in films of $\mathbf{1 b}, \mathbf{1 d}$ and $\mathbf{1 h}$, Figure 2), mossy-like behaviour, shown by $\mathbf{1 c}\left(R^{1}=O M e, R^{2}=H\right.$, Figure, 2$)$ and needle like habits as exemplified by $\mathbf{1 e}\left(R^{1}=R^{2}=\right.$ Me, Figure 2$)$ and also $\mathbf{1 f}$ [for images of all $\mathbf{1 a - h}$ see ESI]. All of the 1a-h films show lower electrical conductivities, as expected, for an insulator phase - the highest being $\mathbf{1 b}$.

Table 2. Electrical properties of thin films of tetrathiotetracenes (1). ${ }^{\text {a }}$

\begin{tabular}{ccccccc}
\hline No. & $\mathrm{R}^{1}$ & $\mathrm{R}^{2}$ & Film morphology & $\begin{array}{c}\text { Film } \\
\text { thickness } \\
(\mu \mathrm{m})\end{array}$ & $\begin{array}{c}\sigma_{\text {(in-plane })} \\
\left(\mathrm{S} \mathrm{cm}^{-1}\right)\end{array}$ & $\begin{array}{c}S_{b} \\
\left(\mu \mathrm{V} \mathrm{K} \mathrm{K}^{-1}\right)\end{array}$ \\
\hline $\begin{array}{c}\text { Pristine } \\
\mathbf{1 a}\end{array}$ & $\mathrm{H}$ & $\mathrm{H}$ & blades & ca. 1 & $2.37 \times 10^{-5}$ & 1170 \\
$\mathbf{1 a}$ & $\mathrm{H}$ & $\mathrm{H}$ & blades & 1.13 & $4.33 \times 10^{-5}$ & 855 \\
$\mathbf{1 b}$ & $\mathrm{Me}$ & $\mathrm{H}$ & blades & 0.56 & $3.76 \times 10^{-4}$ & 464 \\
$\mathbf{1 c}$ & $\mathrm{MeO}$ & $\mathrm{H}$ & mossy & 2.89 & $1.34 \times 10^{-4}$ & 374 \\
$\mathbf{1 d}$ & $\mathrm{Ph}$ & $\mathrm{H}$ & blades & var. ${ }^{[\mathrm{b}]}$ & $1.55 \times 10^{-6}$ & n.d. ${ }^{\mathrm{b}]}$
\end{tabular}


Manuscript for J. Matter. Chem. C., Garrett, et al.

\begin{tabular}{ccccccc}
$\mathbf{1 e}$ & $\mathrm{Me}$ & $\mathrm{Me}$ & needles & 1.89 & $1.26 \times 10^{-4}$ & 732 \\
$\mathbf{1 f}$ & $i \mathrm{Pr}$ & $\mathrm{Me}$ & needles & 0.68 & $1.45 \times 10^{-4}$ & 900 \\
$\mathbf{1 g}$ & $\mathrm{Me}$ & $\mathrm{MeO}$ & mossy needles & 1.51 & $1.40 \times 10^{-5}$ & 501 \\
$\mathbf{1 h}$ & $\mathrm{MeO}$ & $\mathrm{MeO}$ & blades & 0.53 & $2.95 \times 10^{-5}$ & 870 \\
\hline
\end{tabular}

a Films of 1 were grown on glass (ISOLAB microscope slides) as previously described ${ }^{2 b}$ at a substrate deposition temperature of $300 \mathrm{~K}$, a pressure of $7 \times 10^{-6} \mathrm{mbar}$, a deposition rate of 45 $\mathrm{ng} \mathrm{cm} \mathrm{cm}^{-2} \mathrm{~s}^{-1}$ and a source temperature of $500 \mathrm{~K}$. The reproducibility across duplicates, including different sample batches, was $\pm 10 \%$ for in plane conductivity and Seebeck constant measurement. For Seebeck measurements a temperature difference of 10 degrees: $t_{c o l d}=305$ $\mathrm{K}$, thot $=315 \mathrm{~K}$ was applied (see ESI). The actual thickness of films obtained was measured with profilometer Dektak 150 using stylus with diameter $12.5 \mu \mathrm{m}$ and stylus force $0.1 \mathrm{mg}$. b Compound had poor volatility under conditions determined and only a partial film was cast (variable thickness, up to $2.02 \mu \mathrm{m}$ ).

Figure 2. Representative mossy (morphology $A$ for $\mathbf{1}$; $R^{1}=M e O, R^{2}=H$ ), needle (morphology $\mathrm{B}$ for $\mathbf{1 f} ; \mathrm{R}^{1}=i \mathrm{Pr}, \mathrm{R}^{2}=\mathrm{Me}$ ) and blade (morphology $\mathrm{C}$ for $\mathbf{1 h}$ ) film morphologies in substituted TTT derivatives. Other members of $\mathbf{1}$ showed morphologies akin to these types (see ESI).

(A)

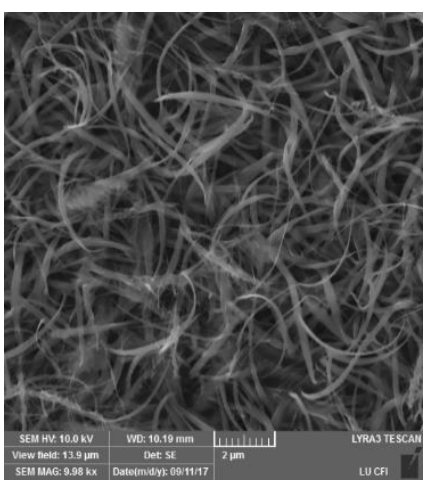

(B)

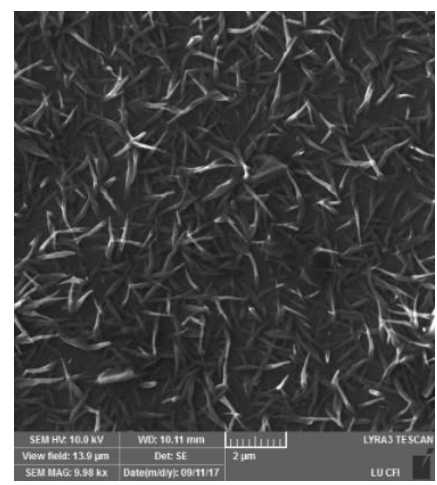

(C)

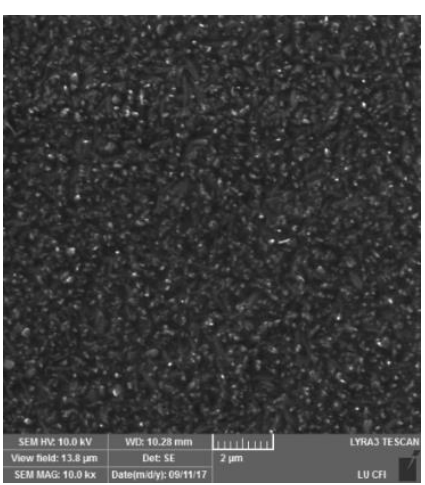

Films of the TTT derivatives $\mathbf{1} \mathbf{a}-\mathbf{h}$ were subjected to post deposition doping with iodine (1 atm., room temperature) as we have previously described (see ESI). ${ }^{2 b}$ Doping was continued until a maximum value of $\sigma_{\text {(in-plane) }}$ was attained. The resultant films were air stable and the $\sigma_{\text {(in-plane) }}$ and $S_{b}$ values attained are shown in Table 3 . The electrical conductivity rose in all cases by factors ranging from 6 to $>10^{4}$ times. Reproducibly the 2,8-disbustituted tetrathiotetracenes $\mathbf{1 e - h}$ led to films showing higher Seebeck coefficients (results highlighted) than the parent material ПT (1a) or other monosubstituted TTTs (1)-c). Normally p-type doping of organic thermoelectric materials promotes a severe collapse in Seebeck performance as electrical conductivity is successively increased by increased $p$-doping. ${ }^{1 a}$ For the parent $\Pi T$ 1a this behaviour significant limits the efficiency of devices built on $T \Pi / I_{2}$ films, ${ }^{2}$ even when their doped stoichiometry of the $\Pi T$ is carefully controlled. Clearly the highlighted $S_{b}$ performance of $I_{2}$ doped $\mathbf{1 e}-\mathbf{h}$ significantly

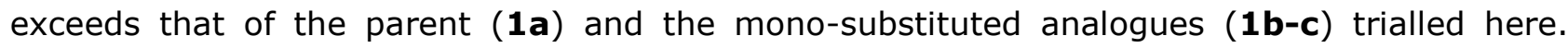
Because of the $\left(S_{b}\right)^{2}$ term in the Power Factor $(P F)$ the present studies strongly suggest that tetrathiotetracenes $\mathbf{1}$ having small electron releasing substituents at the 2,8 positions will be rather good candidates for future OTE devices; e.g. the PF of $\mathbf{1 f}$ in Table is greater than 500x that of 1a used previously. ${ }^{2}$ 
Manuscript for J. Matter. Chem. C., Garrett, et al.

Table 3. Electrical properties of iodine doped thin films of tetrathiotetracenes (1). ${ }^{a}$

\begin{tabular}{ccccccc}
\hline No. & $\mathrm{R}^{1}$ & $\mathrm{R}^{2}$ & $\mathrm{~S} / \mathrm{I}$ ratio & $\begin{array}{c}\sigma_{\text {(in-plane) }} \\
\left(\mathrm{S} \mathrm{cm}^{-1}\right)\end{array}$ & $\begin{array}{c}S_{b} \\
\left(\mu \mathrm{V} \mathrm{K}^{-1}\right)\end{array}$ & $\begin{array}{c}P F \\
\left(\mu \mathrm{W} \mathrm{m} \mathrm{m}^{-1} \mathrm{~K}^{-1}\right)\end{array}$ \\
\hline $\mathbf{1 a}$ & $\mathrm{H}$ & $\mathrm{H}$ & 2.86 & $9.52 \times 10^{-3}$ & 25 & $5.95 \times 10^{-4}$ \\
$\mathbf{1 b}$ & $\mathrm{Me}$ & $\mathrm{H}$ & 2.06 & $7.22 \times 10^{-2}$ & 20 & $2.89 \times 10^{-3}$ \\
$\mathbf{1 c}$ & $\mathrm{MeO}$ & $\mathrm{H}$ & 1.95 & $8.30 \times 10^{-4}$ & 17 & $2.52 \times 10^{-5}$ \\
$\mathbf{1 e}$ & $\mathrm{Me}$ & $\mathrm{Me}$ & 2.85 & $4.42 \times 10^{-3}$ & 85 & $3.20 \times 10^{-3}$ \\
$\mathbf{1 f}$ & $\mathrm{Pr}$ & $\mathrm{Me}$ & 2.92 & $7.00 \times 10^{-2}$ & 216 & $3.27 \times 10^{-1}$ \\
$\mathbf{1 g}$ & $\mathrm{Me}$ & $\mathrm{MeO}$ & 2.08 & $2.25 \times 10^{-2}$ & 48 & $5.27 \times 10^{-3}$ \\
$\mathbf{1 h}$ & $\mathrm{MeO}$ & $\mathrm{MeO}$ & 1.95 & $6.44 \times 10^{-3}$ & 175 & $1.97 \times 10^{-2}$ \\
\hline
\end{tabular}

a The precursor films $\mathbf{1}$ are as described in Table 2. Iodine doping was carried out by cyclic sample exposure to the iodine vapor until the electrical conductivity measured by four contact technique ceased to rise. The cycle lengths varied from 1-3 minutes, depending on the increase of electrical conductivity (see ESI). Such cycling technique has been shown to reduce cracking of $\mathrm{TTT}$ thin films (Ref. 2b). The reproducibility across duplicates, including different sample batches, was $\pm 10 \%$ for in plane conductivity and Seebeck constant measurement. For Seebeck measurements a temperature difference of 10 degrees: $t_{\text {cold }}=305 \mathrm{~K}$, thot $=315 \mathrm{~K}$ was applied (see ESI). b Sulfur:iodine ratio determined from XRF analysis. Based on instrument count statistics, error $\pm 5 \%$.

For the parent $\Pi T\left(R^{1}, R^{2}=H, 1 a\right)$ the following single crystalline phases are known ${ }^{3}$ : $T T I$ (sulfur:iodine $\mathrm{S} / \mathrm{I}$ ratio $=4.00)$, $\mathrm{TT}_{2} \mathrm{I}_{3+\delta}(\delta \sim 0.1$ giving an $\mathrm{S} / \mathrm{I}$ ratio $=2.58)$ and $\Pi_{T} \mathrm{II}_{\sim 2.8}(\mathrm{~S} / \mathrm{I}$ ratio $=1.43$ ) these show highest reported single crystal electrical conductivities of: $70 \mathrm{~S} \mathrm{~cm}^{-1}$, $10^{3} \mathrm{~S} \mathrm{~cm}^{-1}$ and $80 \mathrm{~S} \mathrm{~cm}^{-1}$ respectively. ${ }^{3} \mathrm{X}$-ray fluorescence studies of the films of Table 3 revealed that 1a, 1e and $\mathbf{1 f}$ provided doping with $\mathrm{S} / \mathrm{I}=2.89 \pm 0.04$ while $\mathbf{1 b}-\mathbf{c}$ and $\mathbf{1 g}-\mathbf{h}$ led to S/I $=2.02 \pm 0.06$. The former corresponds to a stoichiometry of approximately ' $T \mathrm{TT}_{3} \mathrm{I}_{4+\delta}{ }^{\prime}(\delta \sim 0.1$ equivalent to $T T T I+T_{T} I_{3+\delta}$, calculated $S / I=2.93$ ) and the latter to ' $T T I_{2}{ }^{2}$. The ATR-IR spectra of iodine doped films of were distinctly different in accord with substituent effects causing two different types of doping regime (see ESI). X-ray photoelectron spectroscopy (XPS) of iodine doped 1 e $\left(R^{1}, R^{2}=M e\right)$ provided an $S / I$ ratio of $2.85 \pm 0.05$ (Figure $S 7 b, E S I$ ) broadly in agreement with the fluorescence data. Attempts at fitting the broad iodine (3d) doublet observed in the XPS of doped 1e were unsuccessful and consistent with the presence of a mixture of iodine oxidation states. This is expected for quasicrystalline behaviour of $\mathrm{TT}_{3} \mathrm{I}_{4+\delta}$ phases where the iodine counter ions are known to be a continuous combination of $\mathrm{I}_{3}{ }^{-}, \mathrm{I}_{2}$ and $\left.\mathrm{I}^{-}\right) .^{3}$ The $\mathrm{S} 2 \mathrm{p}$ region of iodine doped 1e shows a binding energy for sulphur ( $164 \mathrm{eV}$ ) consistent with the sulfur(II) disulphide unit in $\mathbf{1 e}$ still being intact. The presence of two different phases in $\mathbf{1 a - h}$ whose relative population is controlled by the tetrathiotetracene substitution pattern may account for the ease with which the thermoelectric properties of the films can be modified by substituent change. However, as no simple correlation of the crystalline phase type and either $\sigma_{(i n-p l a n e)}, S_{b}$, or $P F$ is found the value of the high throughput screening approach in identifying new cores for OTE application and further study is again demonstrated.

As most state-of-the-art OTE materials are polymers, ${ }^{11}$ hybrid materials ${ }^{12}$ or multilayer systems $^{13}$ direct comparison of our own results with them is very complicated due film morphology and thickness effects on electrical conductivity. Additionally, these literature ${ }^{11-13}$ materials can require inert atmosphere handling, while our results are attained in ambient air. High electrical conductivity and Seebeck values should be a goal to achieve OTEs with high 
Manuscript for J. Matter. Chem. C., Garrett, et al.

operation efficiencies $(Z T>1)$ values as $Z T=\sigma\left(S_{b}\right)^{2} / \kappa$ where $\kappa=$ thermal conductivity. Our reported Seebeck values for pure and doped thin films of $\mathbf{1 f}$ exceeds most of the values reported in literature for state-of-the-art polymeric OTE materials (Table 4 ). ${ }^{1 \mathrm{~b}}$ Moderate to very high Seebeck values have, however been reported for alternative organic systems including pentacene ${ }^{14}$ and $\mathrm{C}_{60}{ }^{15}$ and these are also included in Table 4 for comparison. The electrical conductivity of our TTT derivative thin (designed only for high throughput screening) films are much lower than those employed in many OTE devices. Further study and improvement of our TTT films morphologies will be necessary to increase electrical conductivity without changing Seebeck coefficient and to produce a complete understanding of the electronic and crystal packing effects leading to improved $\sigma$ and $S_{b}$. Evidence that this will be possible is the direct coincidence of Seebeck coefficient values of tetrathiotetracene iodide thin films and monocrystals even though their electrical conductivity differs by a factor of $>10^{4}$. Additionally, better understanding of the TE transport phenomena is attained in the latter. ${ }^{2}$

Table 4. Comparison of our optimal new TTT 1f vs. state-of-the-art OTE materials.

\begin{tabular}{|c|c|c|c|}
\hline OTE [Ref.] & $\sigma_{\text {(in-plane) }}\left(\mathrm{S} \mathrm{cm}^{-1}\right)$ & $S_{b}\left(\mu \vee K^{-1}\right)$ & 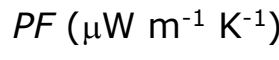 \\
\hline 1f (undoped) & $1.45 \times 10^{-4}$ & 900 & 0.01 \\
\hline $\mathbf{1 f}$ ( $\mathrm{I}_{2}$ doped) & $7.00 \times 10^{-2}$ & 216 & 0.33 \\
\hline PBTTT-C14/FTS [11a] & $\begin{array}{c}604^{\mathrm{a}} / \\
1.1 \times 10^{-1}\end{array}$ & $19^{a}$ & $21.8^{a}$ \\
\hline $\begin{array}{c}\text { PBTTT-C14/ } \\
\text { F4TCNQ }(25 \mathrm{~mol} \%)[11 \mathrm{a}]\end{array}$ & $\begin{array}{c}3.51^{\mathrm{a} /} \\
5.2 \times 10^{-1}\end{array}$ & $60^{a}$ & $1.3^{\mathrm{a}}$ \\
\hline P3HT/FTS [11a] & $\begin{array}{c}27.7^{\mathrm{a}} / \\
1.8 \times 10^{-1}\end{array}$ & $60^{a}$ & $10.0^{a}$ \\
\hline $\begin{array}{c}\text { P3HT/TFSI [11b] } \\
\text { PEDOT/PSS [11f] } \\
\text { Pentacene [14a] } \\
\text { C60 [15] }\end{array}$ & $\begin{aligned} & \sim 89^{\mathrm{b}} \\
& \sim 880^{\mathrm{b}} \\
& 4.3 \times 10^{-1 \mathrm{a}} \\
&<3 \times 10^{-9 a} \\
&\end{aligned}$ & $\begin{array}{c}\sim 46^{\mathrm{b}} \\
\sim 73^{\mathrm{b}} \\
200^{\mathrm{a}} \\
150000^{\mathrm{a}}\end{array}$ & $\begin{array}{c}20 \\
\sim 473^{\mathrm{b}} \\
1.7^{\mathrm{a}} \\
<0.007^{\mathrm{a}} \\
\end{array}$ \\
\hline
\end{tabular}

a Measured under inert nitrogen atmosphere. ${ }^{b}$ Determined from the data of the publication.

\section{Conclusions}

Because the effects of 2 and 2,8-substituents on the thermoelectric properties of TTT molecules (1) were unknown and the synthesis and purification of TTT derivatives can be very time consuming, we set out to attain a method adaptable to high throughput screening of such TTT derivatives for future improved device performance. The recent literature ${ }^{6}$ availability of 2 - and 2,8-disubstituted tetracenes (2) allow a 'direct precipitation' approach to $\mathbf{1 a - h}$ from the $\mathrm{S}_{8}$ containing DMF reaction mixtures to be developed. The substituted TT library (1a-h) is of appropriate purity to allow the deposition of reproducibly pure thin films directly. Both the inplane electrical conductivity and the Seebeck behaviour and $\mathrm{I}_{2}$ doping studies can be therefore carried out quickly and with only small amounts of sample $(10-20 \mathrm{mg})$. The most important conclusion of our work is that 2,8-disubstituted TTT molecules (1e-h) show significantly improved performance in key thermoelectric properties compared to the parent Tा $\mathbf{1} \mathbf{a}$. This is unexpected. Traditionally, it has been assumed that placing substituents in these positions would upset the formation of the 1D stacking that is responsible for the very high electrical conductivity of TTT-I2-based materials. ${ }^{3-4}$ The behaviour of the doped films in $\mathbf{1 e - h}$ in Table 3 is highly encouraging. While considerable work will be required to disentangle substituent, doping and 
Manuscript for J. Matter. Chem. C., Garrett, et al.

morphology effects 2,8-disubstituted $\Pi \pi$ derivatives have been clearly identified as a new privileged core for further OTE optimisation by our screening procedure. If these results are transferable to single crystal studies ${ }^{2 a}$ (and thermal conductivity were not adversely affected) efficient near ambient TTT thermoelectric materials would be realised, as has been long predicted theoretically. ${ }^{16}$

\section{Experimental Section}

Full details of the preparation of $\mathbf{1 a - h}$ and measurement of their properties are given in the ESI.

\section{Conflicts of Interest}

There are no conflicts of interest to declare.

\section{Acknowledgments}

MRG is grateful for the award of an Appalachian College Association Fellowship for sabbatical leave support from Berea College, Kentucky, USA. MJD-P thanks Ayuda Plan Propio supported by University of Cádiz. This work was supported, in part, by National Research Program of Latvia "Multifunctional Materials and Composites, Photonics and Nanotechnology" (IMIS2) project "Nanomaterials and Nanotechnology". We are grateful to Jens Pflaum and his group (Universtität Würzburg) for providing us with a pristine sample of $\Pi \pi$ (1a). SW is grateful to the University of Nottingham for support. An EPSRC grant for the Kratos LiPPS XPS instrument EP/K005138/1 is acknowledged together with Dr Emily F. Smith at the Nanoscale and microscale research centre (nmRC), University of Nottingham for acquiring the XPS spectra and data interpretation.

\section{References}

1. Key overviews of recent OTE developments see: (a) P. J. Taroni, I. Hoces, N. Stingelin, M. Heeney and E. Bilotti, Isrl. J. Chem., 2014, 54, 534-552. (b) B. Russ, A. Glaudell, J. J. Urban, M. L. Chabinyc and R. A. Segalman, Nature Rev. Mater., 2016, 1, 16050. (c) G. Chen, W. Xu and D. Zhu, J. Mater. Chem. C, 2017, 5, 4350-4360.

2. (a) F. Huewe, A. Steeger, K. Kostova, L. Burroughs, I. Bauer, P.Strohriegl, V. Dimitrov, S. Woodward and J. Pflaum, Adv. Mater., 2017, 29, 1605682. (b) K. Pudzs, A. Vembris, M. Rutkis and S. Woodward, Adv. Electron. Mater., 2017, 3, 1600429. (c) K. Pudzs, A. Vembris, J. Busenbergs, M. Rutkis and S. Woodward, Thin Solid Films, 2016, 598, 214218. (d) H. Yoshino, A. Hasegawa, N. Kuroda, R. Tanaka and M. Kozaki in Abstracts of $12^{\text {th }}$ International Symposium on Crystalline Organic Metals Superconductors and Magnets, 24$29^{\text {th }}$ September, 2017, Miyagi, Japan.

3. For example no examples of substituent effects on TTT electrical conductivity $(\sigma)$ is given in the key overview of this area: Extended Linear Chain Compounds, J. S. Miller (Ed.) Plenum Press, New York 1982, Vol. 2, pp. 517. We are also aware of no study on the effect of TTT structure on Seebeck coefficients $\left(S_{b}\right)$.

4. Overviews of TTT materials: (a) T. Otsubo and K. Takimiya, Rev. Heteroatom Chem., 1997, 16, 69-84. (b) T. Otsubo, K. Takimiya and Y. Aso, Phosphorus, Sulfur Silicon Relat. Elem., 1998, 136, 447-462. (c) T. Otsubo, Synlett, 1997, 544-550. (d) M. Bendikov, F. Wudl and D. F. Perepichka, Chem. Rev., 2004, 104, 4891-4945. (e) L. Zhang, S. M. Fakhouri, F. Liu, J. C. Timmons, N. A. Ram and A. L. Briseno, J. Mater. Chem., 2011, 21, 1329-1337.

5. Literature for all known and claimed TTT $\mathbf{1}$ derivatives we are aware of (substituents present given in parentheses): (a) M. Wakaki, S. Ishihara, A. Aratani and M. Ando, Jpn. Kokai Tokkyo Koho, 2000, JP 2000066233 A 20000303, pp. 7 [Chem. Abs., 2000, 132, 187715] (2-R $\mathrm{R}^{1}, 3-\mathrm{R}^{2}, 8-\mathrm{R}^{3}, 9-\mathrm{R}^{4}-\mathrm{TTT}$ s where $\mathrm{R}^{1-4}=\mathrm{H}$, alkyl, halo). (b) B. Hilti, E. Minder and J. Pfeiffer, PCT Int. Appl., 1996, WO 9609629 A1 19960328, pp. 52 [Chem. Abs., 1996, 125, 102251] $\left(2,3,8,9-\left(\mathrm{SC}_{5} \mathrm{H}_{4} \mathrm{~N}\right)_{4}-\mathrm{TTT}\right)$. (c) E. Minder and W. Hofherr, Can. Pat. Appl., 1994, CA 2100407 A1 19940116, pp. 15 [Chem. Abs., 1994, 121, 71617] (TTT and 2-F-TTT). (d) W. Hofherr, E. Minder, B. Hilti and J. P. Ansermet, Eur. Pat. Appl., 1993, EP 521826 A1 19930107, pp. 13 [Chem. Abs., 1993, 119, 260554] (2-R $\mathrm{R}^{1}, 3-\mathrm{R}^{2}, 8-$ $\mathrm{R}^{3}, 9-\mathrm{R}^{4}-\mathrm{TTT}$, where $\mathrm{R}^{1}=\mathrm{H}, \mathrm{F}, \mathrm{Cl}$, or $\mathrm{Me} ; \mathrm{R}^{2-4}=\mathrm{H}, \mathrm{R}^{1-4}=\mathrm{F}$ or $\mathrm{CH}_{3}, \mathrm{R}^{1,2}=\mathrm{F}, \mathrm{Cl}$, or $\mathrm{Me}$ and $\mathrm{R}^{3,4}=\mathrm{H}$, or $\mathrm{R}^{1,3}$ or $\mathrm{R}^{1,4}=\mathrm{F}$ and $\mathrm{R}^{2,4}$ or $\left.\mathrm{R}^{2,3}=\mathrm{H}\right)$. (e) H. Miyamoto, K. Takimiya, $\mathrm{Y}$. Aso, $\mathrm{T}$. 
Manuscript for J. Matter. Chem. C., Garrett, et al.

Otsubo and F. Ogura, Synth. Met., 1991, 42, 2389-2392 (2,3-Me2-TTT and 2,3,8,9-MeTTT). (f) T. Maruo, M. T. Jones, M. Singh and N. P. Rath, Chem. Mater., 1991, 3, 630-634 (2,3-diMe-TTT). (g) T. Maruo, M. Singh, M. Jones, R. Thomas, P. Nigam and D. Min, Mater. Res. Soc. Symp. Proc. (Adv. Org. Solid State Mater.), 1990, 173, 149-154 (2,3-diMe-TTT and related compounds). (h) T. Maruo, M. Singh and M. T. Jones, NATO ASI Series, Series B: Physics (Lower-Dimens. Syst. Mol. Electron.), 1990, 248, 191-196 (2,3-diMe-TTT). (i) No Inventor data available, Jpn. Kokai Tokkyo Koho, 1990, JP 02119976 A 19900508, pp. 14. [Chem. Abs., 1991, 114, 155216] (2- $\mathrm{R}^{1}, 3-\mathrm{R}^{2}$-disusbtituted-TTs where $\mathrm{R}^{1}=\mathrm{C}_{1-30}$ alkyl, $\mathrm{CF}_{3}, \mathrm{OR}^{\prime}, \mathrm{SR}^{\prime}$, or $\mathrm{CO}_{2} \mathrm{R}^{\prime}$; and $\mathrm{R}^{2}=\mathrm{H}, \mathrm{C}_{1-30}$ alkyl, $\mathrm{CF}_{3}, \mathrm{OR}^{\prime}, \mathrm{SR}^{\prime}$, or $\mathrm{CO}_{2} \mathrm{R}^{\prime}\left(\mathrm{R}^{\prime}=\mathrm{C}_{1-30}\right.$ alkyl or fluoroalkyl). (j) B. Tieke, A. Wegmann, W. Fischer, B. Hilti, C. W. Mayer and J. Pfeiffer, Thin Solid Films, 1989, 179, 233-238 (2-n-octyloxy-TTT). (k) B. Tieke and A. Wegmann, Thin Solid Films, 1989, 179, 109-120 (2-CF3-TTT and 2-n-octyloxy-TTT). (I) M. Baumann, C. Mayer, W. Wernet and W. Fischer, Eur. Pat. Appl., 1989, EP 344112 A2 19891129, pp. 12 [Chem. Abs., 1990, 112, 216483] (2-CF -TTT). (m) M. Baumann, W. Fischer, V. Kvita, C. W. Mayer and W. Wernet, Eur. Pat. Appl., 1989, EP 344111 A2 19891129, pp. 19 [Chem. Abs., 1990, 113, 115288] (2-CF3-TTT). (n) J. Finter, B. Hilti, C. W. Mayer, E. Minder and J. Pfeiffer, Eur. Pat. Appl., 1988, EP 285564 A1 19881005, pp. 22 [Chem. Abs., 1989, 110, 155481] $\left(2-\mathrm{R}^{1}, 3-\mathrm{R}^{2}, 8-\mathrm{R}^{3}, 9-\mathrm{R}^{4}-\mathrm{TTT}\right.$, where $\mathrm{R}^{1}-\mathrm{R}^{2}=\mathrm{H}, \mathrm{F}, \mathrm{Me}$, alkyl; $\mathrm{R}^{3}-\mathrm{R}^{4}=\mathrm{COR}^{5}\left(\mathrm{R}^{5}=\right.$ halo, $\mathrm{OH}, \mathrm{NH}_{2}$, etc. $) ; \mathrm{R}^{3}$ and $\mathrm{R}^{4}=\mathrm{CO}_{2} \mathrm{CO}, \mathrm{CONR}^{6} \mathrm{CO}\left(\mathrm{R}^{6}=\mathrm{H}\right.$, residue of primary amine). (0) C. W. Mayer, V. Kvita and J. Pfeifer, Ger. Offen. 1985, DE 3510092 A1 19850926, pp. 23. [Chem. Abs., 1986, 105, 235738] (2-COR, 3-R ${ }^{1}-\mathrm{TTT}$ where $\mathrm{R}=\mathrm{C}_{1-12}$ alkoxy, $\mathrm{C}_{5-16}$ cycloalkoxy, $\mathrm{C}_{2-12} \omega$-hydroxyalkoxy, $\mathrm{C}_{6-16}$ aryloxy, $\mathrm{C}_{7-12}$ aralkoxy, $\mathrm{OH}, \mathrm{NH}_{2}, \mathrm{Cl}, \mathrm{Br}$, monosubstituted amino; $\mathrm{R}^{1}=\mathrm{H}, \mathrm{COR}$, or $\mathrm{RR}^{1}$ together may be $\mathrm{CO}_{2}$ or $\mathrm{N}$-substituted CON). (p) V. Kampars and O. Neilands, Zh. Obsh. Khim., 1979, 49, 2558-2560 (2-tBu-TTT and 2-MeO-TTT). (q) O. N. Eremenko, A. Livdane, R. Medne, O. Neilands, M. L. Khidekel and E. B. Yagubskii, Izv. Akad. Nauk SSSR, Ser. Khim. 1977, 696-697 [Chem. Abs., 1977, 87, 39160] (2-tBu-TTT). (r) J. Freimanis and A. R. Voron'ko, Latvijas PSR Zinatnu Akademijas Vestis, Kimijas Serija, 1977, 90-93 [Chem. Abs., 1977, 86, 189773] (2-iPr-TTT).

6. S. Woodward, M. Ackermann, S. Ahirwar, L. Burroughs, M. R. Garrett, J. Ritchie, J. Shine, B. Tyril, K. Simpson and P. Woodward, Chem. Eur. J., 2017, 23, 7819-7824.

7. E. A. Perez-Alberne, U.S. Patent 3723417 A 19730327, 1973, pp. 4 [Chem. Abs., 1973, 78, 159696].

8. O. Dideberg and J. Toussaint, Acta Cryst., Sec. B, 1974, 30B, 2481-2485.

9. R. Grzibovskis, A. Vembris and K. Pudzs, J. Phys. Chem. Solids, 2016, 95, 12-18.

10. J.-L. Bredas, Mater. Horiz., 2014, 1, 17-19.

11. (a) A. M. Glaudell, J. E. Cochran, S. N. Patel and M. L. Chabinyc, Adv. Energy Mater., 2015, 5, 1401072. (b) Q. Zhang, Y. Sun, W. Xu and D. Zhu, Energy Environ. Sci., 2012, 5, 96399644. (c) Q. Zhang, Y. Sun, W. Xu and D. Zhu, Adv. Mater., 2014, 26, 6829-6851. (d) O. Bubnova, Z. U. Khan, A. Malti, S. Braun, M. Fahlman, M. Berggren and X. Crispin, Nature Mater., 2011, 10, 429-433. (e) Q. Wei, M. Mukaida, K. Kirihara, Y. Naitoh and T. Ishida, Mater., 2015, 8, 732-750. (f) G.-H. Kim, L. Shao, K. Zhang and K. P. Pipe, Nature Mater., 2013, 12, 719-23.

12. E. Jin Bae, Y. Hun Kang, K.-S. Jang and S. Yun Cho, Nature Sci. Rep., 2016, 6, 18805.

13. (a) C. Cho, K. L. Wallace, P. Tzeng, J. H. Hsu, C. Yu and J. C. Grunlan, Adv. Energy Mater., 2016, 6, 1-8. (b) C. Cho, B. Stevens, J.-H. Hsu, R. Bureau, D A. Hagen, O. Regev, C. Yu and J. C. Grunlan, Adv. Mater., 2015, 27, 2996-3001.

14. (a) K. Harada, M. Sumino, C. Adachi, S. Tanaka and K. Miyazaki, App. Phys. Lett. 2010, 96, 253304. Higher Seebeck values (ca. 250-500 $\mu \mathrm{V} \mathrm{K}^{-1}$ ) have been reported but at low current, see: (b) A. von Mühlenen, N. Errien, M. Schaer, M.-N. Bussac, and L. Zuppiroli, Phys. Rev. B, 2007, 75, 115338. (c) A. A. Günther, J. Widmer, D. Kasemann, and K. Leo App. Phys. Lett., 2015, 106, 233301.

15. H. Kojima, R. Abe, M. Ito, Y. Tomatsu, F. Fujiwara, R. Matsubara, N. Yoshimoto, and M. Nakamura, App. Phys. Expr., 2015, 8, 121301.

14. S. Andronic and A. Casian, Adv. Mater. Phys. Chem., 2017, 7, 212-222 and references therein. 
Manuscript for J. Matter. Chem. C., Garrett, et al.

\section{Graphical Abstract and Table of Contents text}

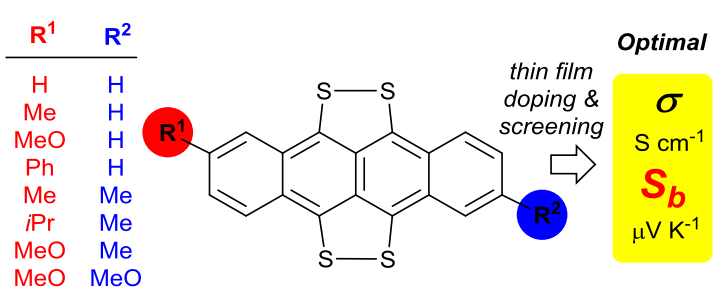

Thermoelectric properties (conductivity and Seebeck coefficient) are in screening for new tetrathiotetracene lead materials. Iodine doping reveals $i \mathrm{Pr}, \mathrm{Me}-\mathrm{TTT}$ as optimal. 